\title{
Naltrexone Improves Quit Rates, Attenuates Smoking Urge, and Reduces Alcohol Use in Heavy Drinking Smokers Attempting to Quit Smoking
}

\author{
Daniel J. Fridberg, Dingcai Cao, Jon E. Grant, and Andrea C. King
}

\begin{abstract}
Background: Heavy drinking smokers (HDS) have more difficulty quitting smoking than lighter drinkers or abstainers. The opioid antagonist naltrexone may improve smoking quit rates and reduce alcohol use in drinker-smokers, but its relative efficacy in smokers with a range of drinking patterns is unknown. The current study tested the hypothesis that HDS would show differential benefit of naltrexone versus placebo relative to moderate-to-light or nondrinking smokers in terms of improving smoking outcomes and reducing alcohol consumption.

Methods: Adult smokers $(N=315)$ enrolled in a 12-week, double-blinded, placebo-controlled trial of $50 \mathrm{mg}$ naltrexone for smoking cessation were categorized into subgroups based upon past 6-month drinking patterns: HDS ( $n=69$; i.e., averaged $\geq 2$ heavy drinking episodes per month), moderate-tolight drinking smokers $(n=204$, i.e., consumed 1 drink up to a maximum of $<2$ heavy drinking episodes per month on average), or nondrinking smokers $(n=42$, no alcohol consumed in the past 6 months). The groups were compared on the main study outcomes of biochemically verified prolonged abstinence quit rates (i.e., no smoking weeks 2 to 12), and smoking urge and alcohol use (drinks/wk) during treatment.

Results: Naltrexone significantly increased 12-week smoking abstinence rates and decreased smoking urge and alcohol use among HDS, but not moderate-to-light or nondrinking smokers. Mediation analyses in HDS revealed that naltrexone's effect on smoking urge during the first 4 weeks of treatment mediated its effect on quit rates.

Conclusions: HDS appear to be particularly sensitive to naltrexone effects on smoking and drinking outcomes. This group may represent an important target for adjunctive treatment with naltrexone to optimize smoking cessation outcomes.
\end{abstract}

Key Words: Naltrexone, Heavy Drinking, Alcohol, Smoking Cessation.

$\mathrm{T}$ WENTY PERCENT OF adults in the United States smoke cigarettes (Schoenborn et al., 2013). Tobacco use is the leading cause of preventable death in the United States, accounting for over 440,000 deaths per year (Schoenborn et al., 2013). While two-thirds of adult smokers express a desire to quit, only about $6 \%$ are successful (Centers for Disease Control and Prevention, 2011). Quitting smoking may be especially difficult for smokers who drink, as alcohol use is associated with lower smoking cessation rates (Agudo et al., 2004; Humfleet et al., 1999; Hymowitz et al., 1997; Leeman et al., 2008; Osler et al., 1999; Prochaska et al., 2008; Shiffman, 1982). Specifically, smokers who drink heavily

From the Department of Psychiatry \& Behavioral Neuroscience (DJF, JEG, ACK), The University of Chicago, Chicago, Illinois; and Department of Ophthalmology \& Visual Sciences (DC), University of Illinois at Chicago, Chicago, Illinois.

Received for publication January 31, 2014; accepted July 10, 2014.

Reprint requests: Andrea C. King, PhD, Department of Psychiatry \& Behavioral Neuroscience, The University of Chicago, 5841 S. Maryland Avenue, MC-3077, Chicago, IL 60637; Tel.: 773-702-6181; Fax: 773702-0096; E-mail: aking@bsd.uchicago.edu

Copyright (C) 2014 by the Research Society on Alcoholism.

DOI: 10.1111/acer.12513 (i.e., consuming 5 or more drinks in an occasion for men, 4 or more for women) have poorer quit rates than smokers who do not drink or who drink in moderation (Dawson, 2000; Kahler et al., 2009). These poorer smoking outcomes in heavy drinking smokers (HDS) have been hypothesized to be due to alcohol, particularly at high doses, triggering smoking urge and acting as an interoceptive or exteroceptive cue to smoking behavior (Epstein et al., 2007; King and Epstein, 2005; King et al., 2009b; Rohsenow et al., 1997; Sayette et al., 2005). Thus, decreased alcohol consumption may be associated with better outcomes in HDS during a smoking quit attempt (Kahler et al., 2008). Despite the importance of targeted interventions for comorbid drinker-smokers, there have been no treatments approved for this purpose to date.

Naltrexone is an opioid receptor antagonist approved for the treatment of opioid and alcohol dependence and has been under investigation for tobacco dependence (David et al., 2013). While a recent meta-analysis of 8 clinical trials found that naltrexone (vs. placebo) did not significantly improve biochemically verified smoking abstinence rates at 6-month follow-up (David et al., 2013), naltrexone has been shown to reduce urge to smoke and smoking behavior, and increase quit rates during 4 to 12 weeks of active treatment (King et al., 2012; O’Malley et al., 2006). It has been posited 
that naltrexone combined with nicotine replacement may reduce smoking by both decreasing the reinforcing effects of smoking and decreasing the severity of withdrawal symptoms (Krishnan-Sarin et al., 1999). Further, among HDS in smoking cessation, naltrexone has been shown to reduce alcohol consumption and heavy drinking episodes through 4 to 6 weeks of treatment (King et al., 2009a; O'Malley et al., 2009). Naltrexone also marginally improved smoking quit rates in a small sample of $\operatorname{HDS}(n=36)$ at 4 weeks $(80 \%$ with naltrexone vs. $52 \%$ with placebo, $p=0.09$ ) (King et al., 2009a). It remains unclear whether HDS show differential efficacy of naltrexone for both smoking and drinking outcomes compared with moderate-to-light drinkers or nondrinkers, and what mechanisms may underlie such effects.

We recently conducted the largest double-blind, placebocontrolled trial of $50 \mathrm{mg}$ naltrexone for smoking cessation and showed that naltrexone increased smoking quit rates during active treatment compared with placebo (King et al., 2012). In the current secondary analysis, we investigated the efficacy of naltrexone on smoking and drinking outcomes as a function of participants' drinking background, comparing responses in HDS to both moderate-to-light and nondrinking smokers. We predicted that HDS, compared with moderate-to-light and nondrinkers, would show the most benefit from naltrexone treatment relative to placebo, with higher smoking quit rates and greater reductions in smoking urge and alcohol consumption (King et al., 2009a). Further, we explored naltrexone's effects on smoking urge and alcohol use as potential mediators of its effect on quit rates in HDS.

\section{MATERIALS AND METHODS}

\section{Participants}

Smokers desiring to quit $(N=315)$ were recruited via local media and Internet advertisements and word-of-mouth referrals to participate in a randomized clinical trial of the efficacy of naltrexone for smoking cessation (for study details, see King et al., 2012). Eligible participants were between 18 and 65 years of age, smoked 10 to 40 cigarettes/d for at least 2 years, had no past year history of DSM-IV Axis I disorders including alcohol or drug dependence (excluding nicotine), no lifetime opioid use disorders, and were generally healthy. All participants provided informed consent, and the study was fully approved by the University of Chicago Institutional Review Board.

\section{Treatment Conditions}

Treatment consisted of randomization to either naltrexone or placebo, both in conjunction with open-label nicotine patch and behavioral therapy (for details, see King et al., 2012). Participants received their assigned study drug 1 week prior to their quit date and continued to quit date and the next 12 weeks. For naltrexone, the dose in the prequit week was titrated from $12.5 \mathrm{mg} / \mathrm{d}$ (day 1) to $25 \mathrm{mg} / \mathrm{d}$ (days 2 and 3) and then to the target dose of $50 \mathrm{mg} / \mathrm{d}$ (day 4 through the end of the trial); identical placebos were also given with the same titration. The nicotine patch was started on the quit date and continued at $21 \mathrm{mg} / \mathrm{d}$ for the first 2 weeks, and then downtitrated to $14 \mathrm{mg} / \mathrm{d}$ in the third week, $7 \mathrm{mg} / \mathrm{d}$ in the fourth week, and then discontinued. Medication compliance was assessed by interview and by collection of any unused tablets at each study visit and quantified as each participant's ratio of the number of tablets taken to the number disbursed (King et al., 2013). Adherence to naltrexone was confirmed via concentrations of naltrexone and its major metabolite, 6- $\beta$-naltrexol, obtained from urine and saliva samples (King et al., 2013). Behavioral therapy consisted of six 45minute weekly individual sessions with a master's- or doctoral-level clinician (Courage to Quit ${ }^{\circledR}$ 2008, Respiratory Health Association of Metropolitan Chicago, Chicago, IL; Asvat et al., 2014) starting from 2 weeks prior to the quit date to the fourth week after the quit date and then discontinued (i.e., at the same time as patch). For the next 8 weeks, the study drug continued daily and participants attended biweekly medication disbursement and assessment visits, with active treatment discontinued at 12 weeks after the quit date. Participants who completed the 12-week active treatment phase were recontacted at the 6- and 12-month postquit date to examine the effects of the medication condition on longer-term outcomes.

\section{Assessment}

Smoking, Smoking Urge, and Alcohol Use. At pretreatment baseline, participants completed demographic and smoking history questionnaires as well as the Fagerström Test of Nicotine Dependence (FTND; Heatherton et al., 1991). They also underwent an alcohol quantity-frequency interview (QFI; Cahalan et al., 1969) for past 6 months estimations of typical drinking frequency and quantity, maximum quantity, and frequency of heavy drinking (defined as $\geq 4$ drinks for women or $\geq 5$ drinks for men in a single occasion). During pretreatment baseline and at each study visit, participants underwent a Timeline Followback interview (Sobell and Sobell, 1995) to assess daily estimation of smoking and drinking behaviors. Subjective smoking urge was assessed at each study visit using the total score from the 10-item Brief Questionnaire of Smoking Urges (BQSU; Cox et al., 2001). Smoking abstinence at each study visit and at 6- and 12-month follow-ups was verified using a breath test for carbon monoxide, with values $<10 \mathrm{ppm}$ indicating smoke-free status.

Drinking Subgroup Classifications. Based on the past 6-month QFI, participants were classified into 3 drinking subgroups, including HDS ( $n=69 ; 34$ naltrexone) who averaged $\geq 2$ heavy drinking episodes per month, moderate-to-light drinking smokers $(n=204$; 107 naltrexone) who consumed at least 1 drink up to a maximum of $<2$ heavy drinking episodes per month on average, and nondrinking smokers ( $n=42 ; 20$ naltrexone) who reported no alcohol consumption. The rationale for these subgroups was that frequent heavy drinking departs from normative social drinking levels (NIAAA, 2005; SAMHSA, 2013) and to allow direct comparison to our prior research (King et al., 2009a). This classification has the advantage over the National Institute on Alcohol Abuse and Alcoholism hazardous drinking criteria of 7 or more drinks weekly for women (14 for men) (NIAAA, 2005), as frequent light drinkers may meet those criteria without engaging in heavy drinking episodes. Further, the validity of these subgroups yielding differential severity of alcohol drinking was supported by other consumption measures, including amount and frequency of alcohol consumption, maximum alcohol consumption in a single 24-hour period, and percentage of heavy drinking days (Table 1).

Adverse Effects and Adherence. As reported previously (King et al., 2012), in the first week of treatment, participants in the naltrexone group compared with placebo reported a greater incidence of nausea ( $48 \%$ vs. $23 \%$ placebo; $p<0.01)$ and dizziness $(48 \%$ vs. $34 \%$ placebo; $p<0.05$ ), but there were no differences in adverse effects by week 4 and thereafter. Nausea is the most common adverse effect of naltrexone (Croop et al., 1997). Of note, the main results described below remained significant when mean nausea rating over the 12-week trial was included as a covariate in the models. Medication compliance did not differ by group ( $75 \%$ for naltrexone, 
Table 1. Demographic, Alcohol Use, and Smoking Information by Drinker Subgroup

\begin{tabular}{|c|c|c|c|c|}
\hline Variable & $\begin{array}{c}\text { Non drinker } \\
(n=42 ; 20 \text { naltrexone })\end{array}$ & $\begin{array}{c}\text { Moderate-light drinker } \\
(n=204 ; 107 \text { naltrexone })\end{array}$ & $\begin{array}{c}\text { Heavy drinker } \\
(n=69 ; 34 \text { naltrexone })\end{array}$ & $p$ \\
\hline Age (year) & $49.5(10.0)^{\mathrm{a}}$ & $42.6(10.5)^{b}$ & $35.5(10.8)^{\mathrm{c}}$ & $<0.001$ \\
\hline Education (year) & $14.2(1.9)^{\mathrm{a}}$ & $15.3(2.4)^{b}$ & $14.9(1.9)^{a, b}$ & $<0.05$ \\
\hline Race (\% Caucasian) & $33 \%^{\mathrm{a}}$ & $61 \%$ & $63 \% \mathrm{~b}$ & $<0.01$ \\
\hline Sex (\% Male) & $43 \%{ }^{a}$ & $42 \%{ }^{a}$ & $62 \%{ }^{b}$ & $<0.05$ \\
\hline Retention rate & $71 \%$ & $78 \%$ & $71 \%$ & 0.41 \\
\hline \multicolumn{5}{|l|}{ Drinking } \\
\hline Drinking days/wk & $-(-)^{a}$ & $1.5(1.5)^{\mathrm{b}}$ & $2.8(1.7)^{\mathrm{C}}$ & $<0.001$ \\
\hline Drinks/drinking day & $-(-)^{a}$ & $2.8(1.5)^{b}$ & $5.5(3.0)^{\mathrm{c}}$ & $<0.001$ \\
\hline Max \# drinks in 24 hour & $-(-)^{a}$ & $4.9(3.5)^{b}$ & $12.6(6.3)^{\mathrm{c}}$ & $<0.001$ \\
\hline$\%$ Heavy drinking days/month & $-(-)^{a}$ & $1.2 \%(1.5)^{\mathrm{a}}$ & $22.7 \%(19.6)^{b}$ & $<0.001$ \\
\hline Past alcohol dependence (\%) & $33 \%$ & $10 \%^{\mathrm{b}}$ & $20 \%{ }^{\mathrm{c}}$ & $<0.001$ \\
\hline \multicolumn{5}{|l|}{ Smoking } \\
\hline Cigarettes per day, baseline & $17.4(5.7)$ & $16.3(5.0)$ & $15.6(5.6)$ & 0.22 \\
\hline Smoking urge (baseline BQSU score) & $29.5(10.9)$ & $29.3(11.6)$ & $30.1(10.5)$ & 0.89 \\
\hline Fagerström score & $5.9(1.9)^{a}$ & $5.3(1.8)^{b}$ & $4.8(1.84)^{b}$ & 0.01 \\
\hline Smoking duration (year) & $32.6(10.1)^{\mathrm{a}}$ & $24.4(11.0)^{\mathrm{b}}$ & $18.0(11.1)^{\mathrm{C}}$ & $<0.001$ \\
\hline Previous quit attempts ( $>12$ hour; \#) & $3.5(3.9)$ & $4.7(8.6)$ & $3.7(3.6)$ & 0.57 \\
\hline
\end{tabular}

BQSU, Brief Questionnaire of Smoking Urges. Nondrinkers reported no alcohol use in the 6 months prior to their enrollment in the study. All variables were compared across drinker subgroups using analysis of variance, with the exception of sex, race, and past alcohol dependence (chi-square). Significant differences between subgroups $(p<0.05)$ are indicated by differing superscripts. Values are mean (SD) unless otherwise indicated.

$74 \%$ for placebo, $F=0.10, p=0.75)$, drinker subgroup, sex, or race $(F \mathrm{~s}<0.99, p \mathrm{~s}>0.32)$ and was not correlated with age $(p=0.10)$, education $(p=0.20)$, or the baseline smoking-related variables shown in Table 1 ( $p$ s $>0.21)$. Most participants $(76 \% ; 238 / 315)$ completed the trial with no differences across medication $\left(\chi^{2}=0.13\right.$, $p=0.72)$, drinker subgroups $\left(\chi^{2}=1.79, p=0.41\right)$, sex $\left(\chi^{2}=0.30\right.$, $p=0.59)$, or race $\left(\chi^{2}=3.69, p=0.06\right)$. Similarly, participants who completed the trial did not differ from those who dropped out in terms of age $(p=0.11)$, education $(p=0.07)$, or baseline smokingrelated variables $(p s>0.26)$.

\section{Statistical Analyses}

The primary smoking outcomes were quit rates after 12 weeks of treatment and smoking urge (BQSU score) at each study visit, as the parent trial found a benefit of naltrexone on smoking quit rates at the end of active treatment but not 6- or 12-month follow-up (King et al., 2012). The primary alcohol outcome was weekly number of drinks through treatment. The quit rate was defined as prolonged abstinence, that is, not smoking even 1 puff of a cigarette, allowing an initial 1-week grace period (Hughes et al., 2003), and confirmed with a $\mathrm{CO}$ reading of $\leq 10 \mathrm{ppm}$ at each visit. Participants who dropped out before the end of treatment (24\%) were conservatively classified as relapsed to smoking. Missing data for smoking urge and weekly drinking were not were not imputed.

Logistic regression was used to examine medication effects on prolonged abstinence quit rates across the drinker subgroups. Generalized estimating equation (GEE; Liang and Zeger, 1986) models with a Poisson distribution (with standard errors of the coefficients scaled using the square root of the Pearson chi-square-based dispersion; McCullagh and Nelder, 1989) were used to examine medication effects on alcoholic drinks per week, and GEE models with a gamma distribution were used for BQSU scores. All analyses controlled for their respective baseline values. In addition, as the drinker subgroups differed by age, education, race, sex, FTND scores, and proportion meeting criteria for past alcohol dependence $(p s<0.05$; see Table 1$)$, those variables were included as covariates in the main models assessing medication effects. Additional analyses indicated that the inclusion of these covariates did not change the main results; therefore, the results reported here controlled for the covariates.
Exploratory mediation analyses were conducted to determine whether naltrexone's effects on quit rates in HDS were mediated by its reduction in smoking urge and alcohol use. We tested naltrexone's effect on mean BQSU scores during the first 4 weeks of treatment as a potential mediator because we showed previously that naltrexone significantly reduced smoking urge at 4 weeks after the quit date (King et al., 2013), and we wanted to determine whether that effect would further mediate the effect of naltrexone on quit rate at the end of treatment. For alcohol use, we tested mean change in weekly drinking (relative to baseline) over the course of treatment as a potential mediator of medication effects on quit rates after 12 weeks of treatment. To test mediation, we used the PROCESS macro (Hayes, 2013) in SPSS (IBM Corp., Armonk, NY) with 5,000 bootstrap resamples to generate bias-corrected $95 \%$ confidence intervals (CIs) for the indirect effect of medication on quit rates at the end of active treatment via each potential mediator. Mediation was demonstrated by a $95 \%$ CI for the indirect effect that did not include zero. Unstandardized path coefficients are reported for mediation analyses (Hayes, 2013).

\section{RESULTS}

\section{Quit Rates and Smoking Urge}

Naltrexone produced higher smoking quit rates versus placebo among HDS at the end of 12 weeks of active treatment $[\mathrm{Med} \times$ Group: OR $(95 \% \mathrm{CI})=3.08(1.17$ to 8.06$)$, $p=0.022$; HDS: $32 \%$ naltrexone vs. $14 \%$ placebo, OR $(95 \%$ CI $)=5.18(1.26$ to 21.32), $p=0.023$ (Fig. 1). In contrast, naltrexone had no effects on quit rates versus placebo in moderate-to-light drinkers ( $25 \%$ vs. $24 \%$, respectively, Med: $p=0.60$ ), and in nondrinkers, quit rates were directionally lower with naltrexone versus placebo $(10 \%$ vs. $32 \%$, respectively; Med: $p=0.24)$. Naltrexone had no effect on pointprevalence quit rates at 6-month $(p s>0.39)$ and 12-month ( $p s>0.39$ ) follow-up in any drinker subgroup. Six-month quit rates for naltrexone versus placebo were $27 \%$ and $20 \%$ 


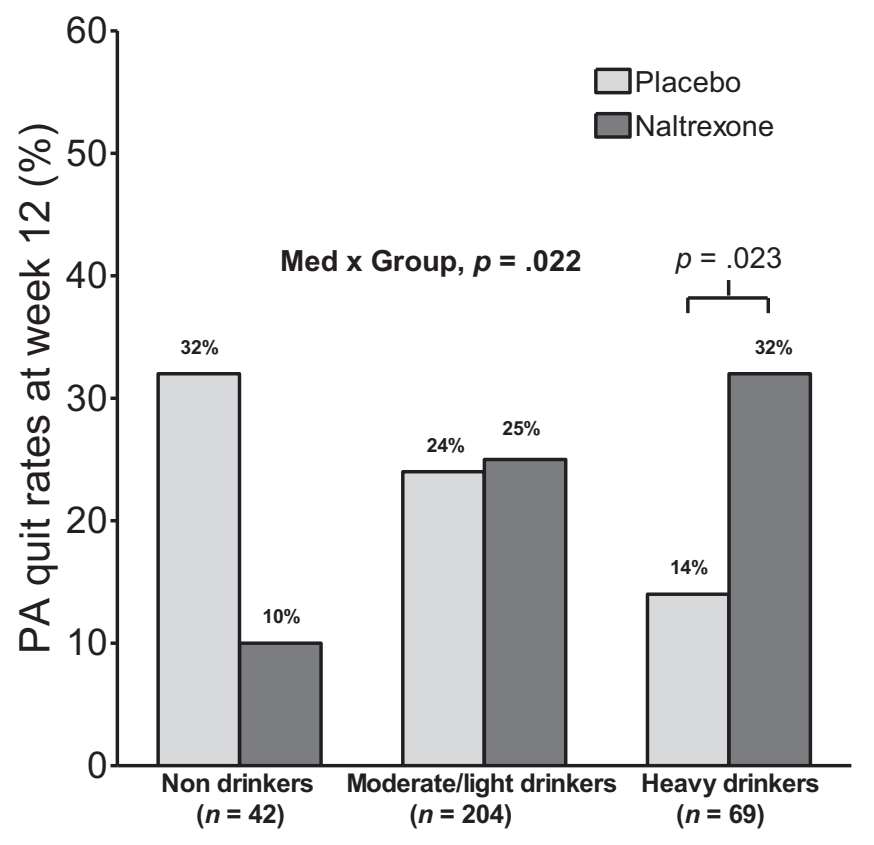

Fig. 1. Prolonged abstinence (PA) quit rates at week 12 for non drinking, moderate-to-light drinking, and heavy-drinking smokers with placebo and naltrexone.

for nondrinkers, $28 \%$ and $27 \%$ for moderate-to-light drinkers, and $20 \%$ and $26 \%$ for heavy drinkers, respectively. Twelve-month quit rates for naltrexone versus placebo were $27 \%$ and $20 \%$ for nondrinkers, $22 \%$ and $19 \%$ for moderateto-light drinkers, and $23 \%$ and $15 \%$ for heavy drinkers, respectively.

Relative to placebo, naltrexone significantly reduced smoking urge $(\mathrm{BQSU})$ in HDS [Med $\times$ Group $\times$ Week: $\beta$ $(\mathrm{SE})=0.0010 \quad(0.0005), \quad 95 \% \quad \mathrm{CI}=0.0001 \quad$ to 0.002 , $p=0.027$; HDS: Med $\times$ Week: $\beta(\mathrm{SE})=0.001 \quad(0.0005)$, $95 \% \mathrm{CI}=0.0002$ to $0.002, p=0.017$ ] (Fig. $2 A$ ). In contrast, naltrexone did not significantly reduce smoking urge in moderate-to-light drinkers and non drinkers $($ Med $\times$ Week $p$ s $>0.33$ ) (Fig. $2 B, C$ ).

\section{Alcohol Use}

Compared with placebo, naltrexone reduced weekly alcohol consumption in HDS [Med $\times$ Group: $\beta(\mathrm{SE})=-0.3462$ $(0.18)$, incidence rate ratio $(\mathrm{IRR})=0.71,95 \% \mathrm{CI}=0.51$ to $1.00, \quad p=0.049$; HDS: Med: $\beta(\mathrm{SE})=-0.3630 \quad(0.13)$, IRR $=0.70,95 \% \mathrm{CI}=0.54$ to $0.90, p=0.005]$ (Fig. $3 A$ ), but this was not the case for moderate-to-light drinking smokers $(p=0.26)($ Fig. 3B).

\section{Mediation Analyses}

We explored the ability of smoking urge and alcohol use to mediate naltrexone's effect on smoking quit rates in HDS. Naltrexone reduced mean BQSU scores over the first 4 weeks of treatment in $\operatorname{HDS}(a(\mathrm{SE})=-0.09(0.04), t$
$(62)=-2.09, p=0.041)$, and BQSU scores predicted quit rates controlling for medication $(b(\mathrm{SE})=-5.28$ (2.40), $z=-2.20, p=0.028)$. The bias-corrected bootstrap CI for the indirect effect was significant, that is, did not contain zero $(a b(\mathrm{SE})=0.48(0.39), 95 \% \mathrm{CI}=0.03$ to 1.52$)$, demonstrating that naltrexone's reduction in smoking urge mediated its effect on quit rates. In contrast, there was no sufficient evidence to confirm an indirect effect of naltrexone on smoking quit rates via reducing alcohol use $(a b(\mathrm{SE})=-0.08(0.18)$, $95 \% \mathrm{CI}=-0.63$ to 0.05$)$.

\section{DISCUSSION}

This double-blind, placebo-controlled study was the first to examine the efficacy of naltrexone for smoking cessation in HDS compared with both moderate-to-light drinking and nondrinking smokers over a 12 -week trial. The main finding was that naltrexone significantly improved prolonged abstinence quit rates in HDS, but not moderate-to-light or nondrinking smokers. Naltrexone also reduced smoking urge and alcohol consumption during treatment among HDS, and its reduction in smoking urge during the first 4 weeks of treatment mediated its effect on quit rates. Collectively, the present results demonstrated that naltrexone improved smoking cessation outcomes in nonalcohol-dependent HDS attempting to quit and reduced their alcohol consumption even though they were neither interested in nor specifically receiving an intervention addressing alcohol use.

Naltrexone reduced alcohol consumption among HDS in the present study, supporting previous reports (King et al., 2009a; O'Malley et al., 2009). Counseling patients on reducing their alcohol intake is only briefly mentioned in current tobacco dependence treatment guidelines (Fiore et al., 2008), despite that alcohol use elicits urge to smoke (Epstein et al., 2007; King and Epstein, 2005; King et al., 2009b; Rohsenow et al., 1997) and is associated with increased odds of relapse to smoking (Dawson, 2000; Kahler et al., 2009). However, HDS are at a disadvantage with the standard treatment approach outlined (smoking counseling + nicotine replacement therapy [NRT]) with quit rates $(14 \%)$ half of those in moderate-to-light or nondrinkers $(24 \%$ and $32 \%$, respectively) (see Fig. 1). Naltrexone appears to reduce this disparity in HDS, with its inclusion in treatment increasing quit rates to $32 \%$. This supports the results of our previous investigation (King et al., 2009a) showing that $50 \mathrm{mg}$ naltrexone marginally improved 4 -week quit rates ( $80 \%$ vs. $52 \%$ with placebo) in HDS. However, another study by O'Malley and colleagues (2009) found no effect of naltrexone $(25,50$, or $100 \mathrm{mg}$ vs. placebo) on 6-week continuous smoking abstinence rates in HDS (range 32 to $50 \%$ ). Discrepancies in results across studies may be due to methodological differences including criteria for heavy/hazardous drinkers, quit rate definition and interval, and dosing and intensity of NRT and behavioral counseling. Thus, replication of the current study results is needed, as well as further examination of the relative contributions of individual treatment components to 
A) Heavy drinkers

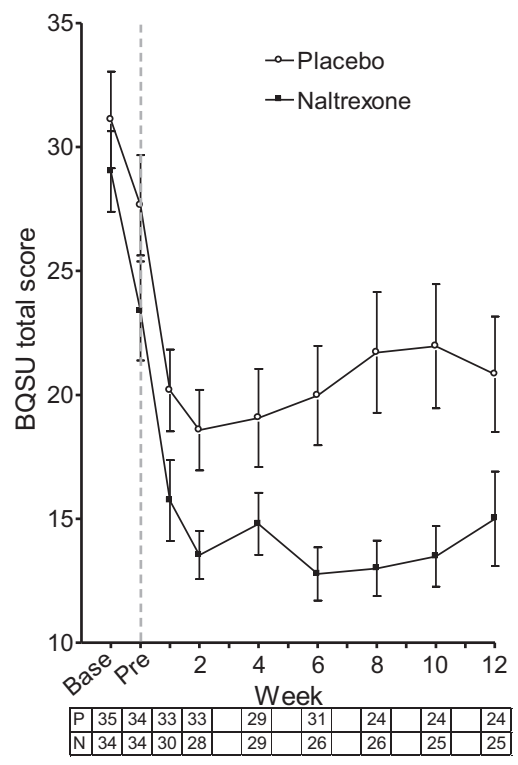

B) Moderate-to-light drinkers

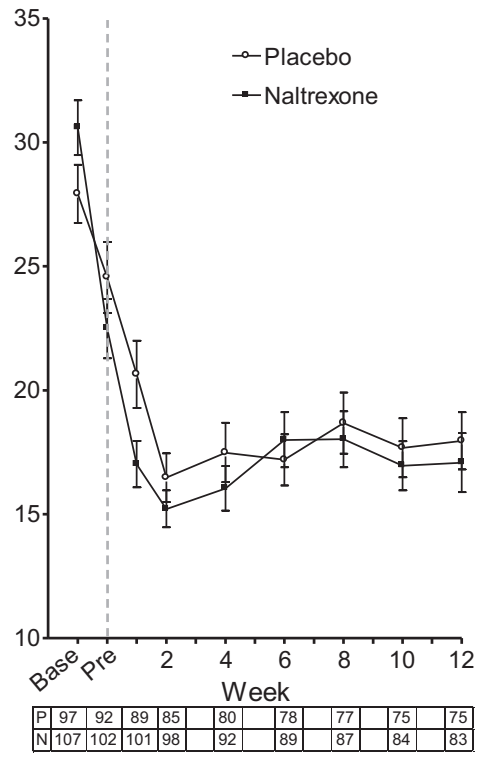

C) Non drinkers

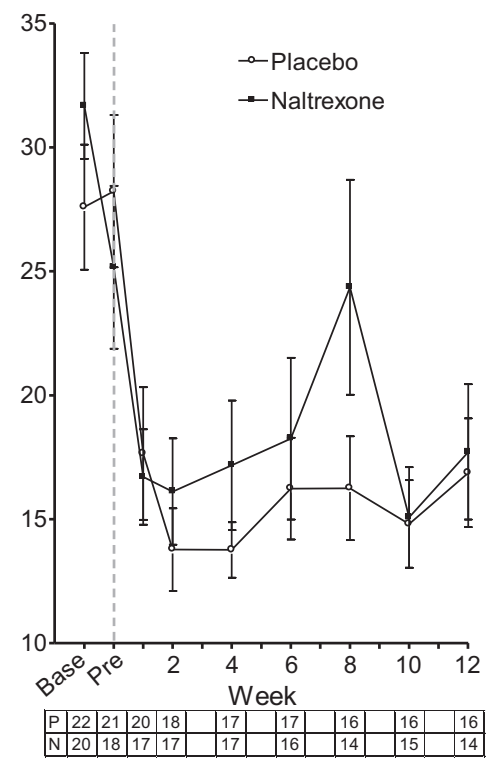

Fig. 2. Effects of naltrexone versus placebo on urge to smoke (BQSU total score) during treatment for the heavy-drinking (A), moderate-to-light drinking (B), and non drinking (C) subgroups. The gray dashed line indicates the first assessment period after initiation of naltrexone or placebo. The number of participants in the placebo $(\mathrm{P})$ and naltrexone $(\mathrm{N})$ conditions at each time point is shown beneath the $x$-axis. Base, baseline assessment; BQSU, Brief Questionnaire of Smoking Urges; Pre, pre-quit week.

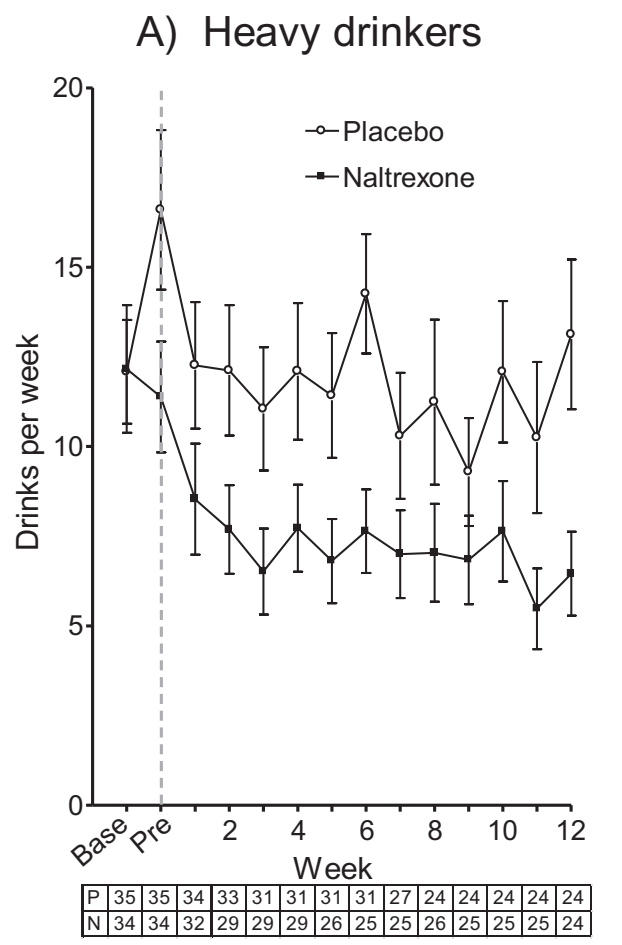

\section{B) Moderate-to-light drinkers}

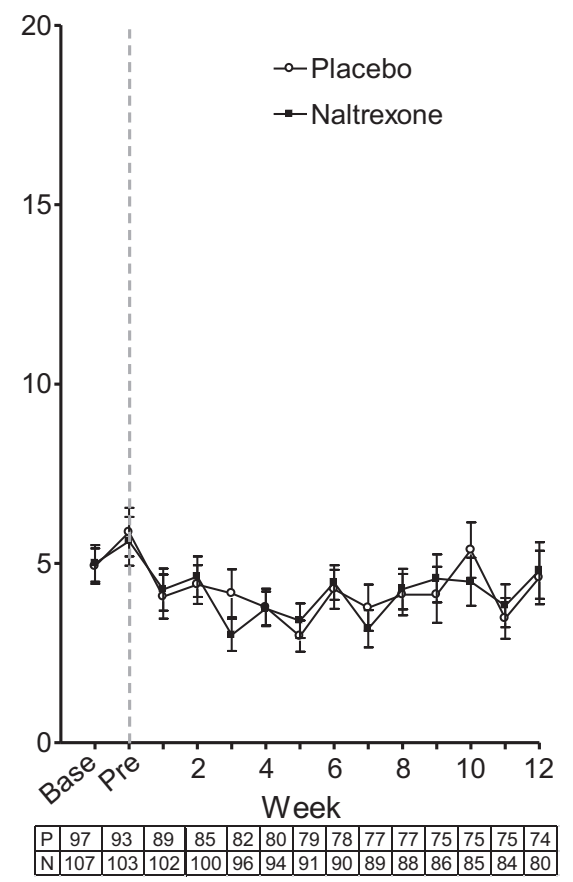

Fig. 3. Effects of naltrexone versus placebo on number of alcoholic drinks consumed per week for the heavy-drinking (A) and moderate-to-light drinking (B) subgroups. The gray dashed line indicates the first assessment period after initiation of naltrexone or placebo. The number of participants in the placebo $(\mathrm{P})$ and naltrexone $(\mathrm{N})$ conditions at each time point is shown beneath the $x$-axis. Base, baseline assessment; Pre, pre quit week.

smoking cessation outcomes across a range of drinking patterns.

In terms of mechanisms, naltrexone's reduction in smoking urge during the first 4 weeks of treatment medi- ated its effect on improving quit rates in HDS. Naltrexone exerts its antagonistic effect primarily at mu-opioid receptors which have been implicated in the rewarding effects of both alcohol (King et al., 1997; Volpicelli et al., 
1995) and nicotine (Benowitz, 1996; Berrendero et al., 2010), and in urge to use those substances (King and Meyer, 2000; Monti et al., 1999; Volpicelli et al., 1992). Of note, naltrexone has been shown to reduce smoking urge at breath alcohol concentrations associated with heavier (i.e., 0.06) but not lighter (i.e., 0.02 to 0.04 ) drinking (Ray et al., 2007), which could explain why naltrexone decreased urge to smoke and increased quit rates relative to placebo among HDS but not moderate-to-light or nondrinking smokers in the present study. Unexpectedly, nondrinking smokers who received placebo showed directionally higher quit rates than those treated with naltrexone (Fig. 1). Medication compliance or dropout did not appear to be a factor in this finding as there were no differences in these outcomes across drinker subgroups. For nondrinkers, adding naltrexone on top of the platform treatment of patch and counseling might have produced nonspecific negative effects of opioid blockage. The nondrinker subgroup had the smallest sample size of the subgroups, so replication in larger samples is needed before firm conclusions may be drawn about whether drinking status should be taken into account when considering naltrexone as an adjunct smoking cessation treatment in patients who have not responded to approved first-line pharmacotherapies. The present findings are similar to those of a recent analysis of the COMBINE data (Fucito et al., 2012) which found that alcohol-dependent individuals with comorbid smoking were more likely to respond to naltrexone in alcohol treatment than alcoholdependent individuals who were nonsmokers. Our findings suggest that the converse may also be true for smoking cessation, as smokers with comorbid heavy drinking appear to be most likely to benefit from naltrexone with nondrinkers showing worse outcomes. Other individual difference factors such as medication expectancy (Colagiuri et al., 2009) and family history of alcohol dependence (King et al., 1997; Tidey et al., 2008) may also moderate naltrexone effects on alcohol outcomes but were beyond the scope of the present study.

The current study featured several strengths, including a large and diverse smoker sample representing a range of drinking patterns, assessment of a longer and potentially more clinically relevant treatment interval than examined in prior studies of naltrexone in HDS (King et al., 2009a; O'Malley et al., 2009), and a consideration of naltrexone's effects on smoking urge and alcohol use as potential mediators of its effect on quit rates. However, there are some limitations worth noting. First, the main study was not designed a priori to examine naltrexone's effects on smoking and drinking behaviors across different drinker subgroups, resulting in uneven samples sizes between groups. Thus, replication in larger samples of drinker-smokers is needed. Second, individuals with current alcohol dependence were excluded from participation, and the counseling sessions focused on smoking cessation and not drinking behaviors per se. Therefore, the present study cannot speak directly to the utility of naltrexone for reducing drinking and smoking in alcohol-dependent smokers or smokers motivated to reduce use of both substances. However, as few patients seek treatment for both substances concurrently, this study and the 2 prior studies in this area (King et al., 2009a; O'Malley et al., 2009) provide important information that naltrexone can reduce drinking in HDS who are neither seeking nor receiving specialized treatment for alcohol issues. Last, the efficacy of naltrexone was examined in the context of other interventions (i.e., NRT and counseling) which prevented us from dismantling the relative contributions of each treatment component (King et al., 2009a).

In conclusion, the current study demonstrated that naltrexone improved quit rates and reduced smoking urges and alcohol consumption among HDS enrolled in a 12-week smoking cessation trial. Further, naltrexone's ability to improve quit rates in HDS was accounted for by its effect on reducing smoking urge during the first 4 weeks of treatment. Notably, naltrexone did not improve quit rates in moderate-to-lightor nondrinking smokers. The present results showing drinking reductions with naltrexone that were exclusive to HDS support 2 prior studies examining only HDS (King et al., 2009a; O'Malley et al., 2009), and the improvement in quit rates in HDS supports our previous study in a smaller sample (King et al., 2009a). By comparing HDS to moderate-to-light and nondrinking smokers, we have demonstrated that HDS selectively benefit from naltrexone as an adjunctive treatment for smoking cessation and may be an important smoker subgroup to target in future clinical trials research.

\section{ACKNOWLEDGMENTS}

This study was supported by a grant from the National Institute of Drug Abuse (\#R01-DA016834), CTSA grant number ULI-RR024999 from the National Center for Advancing Translational Sciences (its contents are solely the responsibility of the authors and do not necessarily represent official views of the National Center for Advancing Translational Sciences or the National Institutes of Health), and the National Cancer Institute (P30-CA14599). The authors would like to acknowledge Ryan Stachoviak, Megan Conrad, Ayodele Gomih, and Michelle Carpentier for providing research support, Lingjiao Zhang, Chuanhong Liao, and Patrick McNamara for database and statistical support, and the study physician, Tracy Wilcox, MD, for providing medical oversight.

\section{REFERENCES}

Agudo A, Pera G, Rodriguez M, Quiros JR, Navarro C, Martinez C, Larrañaga N, Fernandez A, Dorronsoro M, Chirlaque MD, Berenguer A, Barricarte A, Ardanaz E, Amiano P, Tormo MJ, Gonzalez CA (2004) Changes in smoking habits in adults: results from a prospective study in Spain. Ann Epidemiol 14:235-243.

Asvat Y, Cao D, Africk JJ, Matthews A, King A (2014) Feasibility and effectiveness of a community-based smoking cessation intervention in a racially diverse, urban smoker cohort. Am J Pub Health 104(Suppl 4):S620-S627. 
Benowitz NL (1996) Pharmacology of nicotine: addiction and therapeutics. Annu Rev Pharmacol Toxicol 36:597-613.

Berrendero F, Robledo P, Trigo JM, Martín-García E, Maldonado R (2010) Neurobiological mechanisms involved in nicotine dependence and reward: participation of the endogenous opioid system. Neurosci Biobehav Rev 35:220-231.

Cahalan D, Cisin IH, Crossley HM (1969) American Drinking Practices: A National Study of Drinking Behavior and Patterns. Rutgers Center of Alcohol Studies, New Brunswick, NJ.

Centers for Disease Control and Prevention (2011) Quitting smoking among adults-United States, 2001-2010. U.S. Department of Health and Human Services. MMWR Morb Mortal Wkly Rep 60:1513-1519.

Colagiuri B, Morley K, Boakes R, Haber P (2009) Expectancy in doubleblind placebo-controlled trials: an example from alcohol dependence. Psychother Psychosom 78:167-171.

Cox LS, Tiffany ST, Christen AG (2001) Evaluation of the brief questionnaire of smoking urges (QSU-brief) in laboratory and clinical settings. Nicotine Tob Res 3:7-16.

Croop RS, Faulkner EB, Labriola DF (1997) The safety profile of naltrexone in the treatment of alcoholism: results from a multicenter usage study. Arch Gen Psychiatry 54:1130-1135.

David SP, Lancaster T, Stead LF, Evins AE, Prochaska JJ (2013) Opioid antagonists for smoking cessation. Cochrane Database of Systematic Reviews, Issue 6. Art. No.: CD003086. doi: 10.1002/14651858.CD003086. pub3.

Dawson DA (2000) Drinking as a risk factor for sustained smoking. Drug Alcohol Depend 59:235-249.

Epstein AM, Sher TG, Young MA, King AC (2007) Tobacco chippers show robust increases in smoking urge after alcohol consumption. Psychopharmacology 190:321-329.

Fiore MC, Jaén CR, Baker TB, Bailey WC, Benowitz NL, Curry SJ, Dorfman SF, Froelicher ES, Goldstein MJ, Healton CG, Henderson PN (2008) Treating Tobacco Use and Dependence: 2008 Update. Clinical Practice Guideline. U.S. Department of Health and Human Services, Rockville, MD.

Fucito LM, Park A, Gulliver SB, Mattson ME, Gueorguieva RV, O'Malley SS (2012) Cigarette smoking predicts differential benefit from naltrexone for alcohol dependence. Biol Psychiatry 72:832-838.

Hayes AF (2013) Introduction to Mediation, Moderation, and Conditional Process Analysis. The Guilford Press, New York, NY.

Heatherton TF, Kozlowski LT, Frecker RC, Fagerström KO (1991) The Fagerström test for nicotine dependence: a revision of the Fagerström Tolerance Questionnaire. Br J Addict 86:1119-1127.

Hughes JR, Keely JP, Niaura RS, Ossip-Klein DJ, Richmond RL, Swan GE (2003) Measures of abstinence in clinical trials: issues and recommendations. Nicotine Tob Res 5:13-25.

Humfleet G, Muñoz R, Sees K, Reus V, Hall S (1999) History of alcohol or drug problems, current use of alcohol or marijuana, and success in quitting smoking. Addict Behav 24:149-154.

Hymowitz N, Cummings KM, Hyland A, Lynn WR, Pechacek TF, Hartwell TD (1997) Predictors of smoking cessation in a cohort of adult smokers followed for five years. Tob Control 6:S57.

Kahler CW, Borland R, Hyland A, McKee SA, Thompson ME, Cummings KM (2009) Alcohol consumption and quitting smoking in the International Tobacco Control (ITC) Four Country Survey. Drug Alcohol Depend 100:214-220.

Kahler CW, Metrik J, LaChance HR, Ramsey SE, Abrams DB, Monti PM, Brown RA (2008) Addressing heavy drinking in smoking cessation treatment: a randomized clinical trial. J Consult Clin Psychol 76:852-862.

King AC, Epstein AM (2005) Alcohol dose-dependent increases in smoking urge in light smokers. Alcohol Clin Exp Res 29:547-552.

King AC, Cao D, O'Malley SS, Kranzler HR, Cai X, deWit H, Matthews AK, Stachoviak RJ (2012) Effects of naltrexone on smoking cessation outcomes and weight gain in nicotine-dependent men and women. J Clin Psychopharmacol 32:630-636.

King A, Cao D, Vanier C, Wilcox T (2009a) Naltrexone decreases heavy drinking rates in smoking cessation treatment: an exploratory study. Alcohol Clin Exp Res 33:1044-1050.
King A, McNamara P, Conrad M, Cao D (2009b) Alcohol-induced increases in smoking behavior for nicotinized and denicotinized cigarettes in men and women. Psychopharmacology 207:107-117.

King A, Cao D, Zhang L, Rueger SY (2013) Effects of the opioid receptor antagonist naltrexone on smoking and related behaviors in smokers preparing to quit: a randomized controlled trial. Addiction 108:1836-1844.

King AC, Meyer PJ (2000) Naltrexone alteration of acute smoking response in nicotine-dependent subjects. Pharmacol Biochem Behav 66:563-572.

King AC, Volpicelli JR, Frazer A, O'Brien CP (1997) Effect of naltrexone on subjective alcohol response in subjects at high and low risk for future alcohol dependence. Psychopharmacology 129:15-22.

Krishnan-Sarin S, Rosen MI, O'Malley SS (1999) Naloxone challenge in smokers: preliminary evidence of an opioid component in nicotine dependence. Arch Gen Psychiatry 56:663-668.

Leeman RF, McKee SA, Toll BA, Krishnan-Sarin S, Cooney JL, Makuch RW, O'Malley SS (2008) Risk factors for treatment failure in smokers: relationship to alcohol use and to lifetime history of an alcohol use disorder. Nicotine Tob Res 10:1793-1809.

Liang KY, Zeger SL (1986) Longitudinal data analysis using generalized linear models. Biometricka 73:13-22.

McCullagh P, Nelder JA (1989) Generalized Linear Models. 2nd ed. CRC Press LLC, Boca Raton, FL.

Monti PM, Rohsenow DJ, Hutchison KE, Swift RM, Mueller TI, Colby SM, Brown RA, Gulliver SB, Gordon A, Abrams DB (1999) Naltrexone's effect on cue-elicited craving among alcoholics in treatment. Alcohol Clin Exp Res 23:1386-1394.

NIAAA (2005) Helping Patients Who Drink too Much: A Clinician's Guide NIH Publication No. 05-3769. National Institutes of Health, Bethesda, MD.

O’Malley SS, Cooney JL, Krishnan-Sarin S, Dubin JA, McKee SA, Cooney NL, Blakeslee A, Meandzija B, Romano-Dahlgard D, Wu R, Makuch R, Jatlow P (2006) A controlled trial of naltrexone augmentation of nicotine replacement therapy for smoking cessation. Arch Intern Med 166:667-674.

O'Malley SS, Krishnan-Sarin S, McKee SA, Leeman RF, Cooney NL, Meandzija B, Wu R, Makuch RW (2009) Dose-dependent reduction of hazardous alcohol use in a placebo-controlled trial of naltrexone for smoking cessation. Int J Neuropsychopharmacol 12:589-597.

Osler M, Prescott E, Godtfredsen N, Hein HO, Schnohr P (1999) Gender and determinants of smoking cessation: a longitudinal study. Prev Med 29:57-62.

Prochaska JJ, Hall SM, Tsoh JY, Eisendrath S, Rossi JS, Redding CA, Rosen AB, Meisner M, Humfleet GL, Gorecki JA (2008) Treating tobacco dependence in clinically depressed smokers: effect of smoking cessation on mental health functioning. Am J Public Health 98:446-448.

Ray LA, Miranda R Jr, Kahler CW, Leventhal AM, Monti PM, Swift R, Hutchison KE (2007) Pharmacological effects of naltrexone and intravenous alcohol on craving for cigarettes among light smokers: a pilot study. Psychopharmacology 193:449-456.

Rohsenow DJ, Monti PM, Colby SM, Gulliver SB, Sirota AD, Niaura RS, Abrams DB (1997) Effects of alcohol cues on smoking urges and topography among alcoholic men. Alcohol Clin Exp Res 21:101-107.

SAMHSA (2013) Results from the 2012 National Survey on Drug Use and Health: Summary of National Findings, NSDUH Series H-46, HHS Publication No. (SMA) 13-4795, in Series Results from the 2012 National Survey on Drug Use and Health: Summary of National Findings, NSDUH Series H-46, HHS Publication No. (SMA) 13-4795, Substance Abuse and Mental Health Services Administration, Rockville, MD.

Sayette MA, Martin CS, Wertz JM, Perrott MA, Peters AR (2005) The effects of alcohol on cigarette craving in heavy smokers and tobacco chippers. Psychol Addict Behav 19:263-270.

Schoenborn CA, Adams PF, Peregoy JA (2013) Health behaviors of adults: United States, 2008-2010. National Center for Health Statistics. Vital Health Stat 10(257).

Shiffman S (1982) Relapse following smoking cessation: a situational analysis. J Consult Clin Psychol 50:71-86. 
Sobell LC, Sobell MB (1995) Alcohol Timeline Follow-Back Users' Manual. Addiction Research Foundation, Toronto, ON, Canada.

Tidey JW, Monti PM, Rohsenow DJ, Gwaltney CJ, Miranda R, McGeary JE, MacKillop J, Swift RM, Abrams DB, Shiffman S, Paty JA (2008) Moderators of naltrexone's effects on drinking, urge, and alcohol effects in non-treatment-seeking heavy drinkers in the natural environment. Alcohol Clin Exp Res 32:58-66.
Volpicelli JR, Alterman AI, Hayashida M, O'Brien CP (1992) Naltrexone in the treatment of alcohol dependence. Arch Gen Psychiatry 49:876-880.

Volpicelli JR, Watson NT, King AC, Sherman CE, O'Brien CP (1995) Effect of naltrexone on alcohol "high" in alcoholics. Am J Psychiatry 152:613615. 